\title{
Meteor radar observations of mesopause region long-period temperature oscillations
}

\author{
Ch. Jacobi ${ }^{1}$, N. Samtleben ${ }^{1}$, and G. Stober ${ }^{2}$ \\ ${ }^{1}$ Leipzig Institute for Meteorology, Universität Leipzig, Stephanstr. 3, 04103 Leipzig, Germany \\ ${ }^{2}$ Leibniz Institute of Atmospheric Physics at the Rostock University, Schloss-Str. 6, 18225 Kühlungsborn, Germany \\ Correspondence to: Ch. Jacobi (jacobi@uni-leipzig.de)
}

Received: 25 November 2015 - Revised: 21 January 2016 - Accepted: 21 January 2016 - Published: 28 September 2016

\begin{abstract}
Meteor radar observations of mesosphere/lower thermosphere (MLT) daily temperatures have been performed at Collm, Germany since August 2004. The data have been analyzed with respect to long-period oscillations at time scales of 2-30 days. The results reveal that oscillations with periods of up to 6 days are more frequently observed during summer, while those with longer periods have larger amplitudes during winter. The oscillations may be considered as the signature of planetary waves. The results are compared with analyses from radar wind measurements. Moreover, the temperature oscillations show considerable year-to-year variability. In particular, amplitudes of the quasi 5-day oscillation have increased during the last decade, and the quasi 10-day oscillations are larger if the equatorial stratospheric winds are eastward.
\end{abstract}

\section{Introduction}

Mesosphere/lower thermosphere (MLT) winds and temperatures show considerable variability at time scales of several days. These fluctuations, frequently called long-period oscillations, have been attributed to the influence of planetary waves, especially to free oscillations with periods of several days. For example, in an isothermal windless atmosphere the first symmetric and asymmetric Rossby modes have periods of 5 and 8.3 days. In a real situation, the observed frequencies and periods are shifted depending on the tropospheric wind speed and, e.g., for a background wind speed of $10 \mathrm{~m} \mathrm{~s}^{-1}$ the periods change to 5.6 and 10.2 days, respectively (for a review see, e.g., Forbes, 1995). The periods, however, depend on the tropospheric background wind speed and there- fore may change, so that these waves are usually called the quasi 5-day and quasi 10-day waves.

Single station measurements do not permit to characterize these oscillations/waves probably due to the lacking longitudinal information. However, it has been found, in particular through radar wind measurements (e.g. Jacobi et al., 1998a, 2008), that the seasonal variations of these oscillations is very similar to that expected for atmospheric normal modes, so that it is justified to interpret these variations in terms of planetary wave (PW) activity.

To observe PW signatures in temperature profiles, nightglow emissions have been frequently used and analyzed (Espy et al., 1997; Bittner et al., 2000, 2002). These measurements can only be performed during nighttime, and require clear sky conditions, thus these time series contain data gaps. Continuous temperature measurements near the mesopause, however, can also be performed by meteor radar using the decay of individual underdense meteor trails (Hocking, 1999; Hocking et al., 2001). E.g., Stober et al. (2012) have shown that planetary wave oscillations are well reproduced in such data.

PW and their long-term trends have been analyzed frequently using stratospheric data. E.g., Pogoreltsev et al. (2009) found a decrease of the winter quasi 5-, 10-, and 16-day waves in the stratosphere since the 1960s from NCEP/NCAR reanalysis. However, interannual and quasidecadal variability of the waves is large, and the results of linear trend analyses over short time intervals of about one decade may deviate from the long-term trends. For the mesosphere/lower thermosphere (MLT), Jacobi et al. (1998a, 2008) found increasing tendencies for PW in MLT winds, in particular for the zonal component, while for the meridional component the trends are small or negative, which over- 
all results in only slightly positive wind trends. Bittner et al. (2002) did not find a clear long-term trend, but rather indication for an interdecadal variation.

To summarize, the degree of interannual variability of PW in the middle atmosphere is still subject to current research, and new data may lead to new insights into interannual variability and long-term tendencies of the middle atmosphere. Therefore, temperature oscillations over Collm $\left(51.3^{\circ} \mathrm{E}, 13.0^{\circ} \mathrm{N}\right)$ in the period range between 2 and 30 days are analyzed here. We investigate the seasonal cycle, and wave activity changes during the period from 2005 through 2013, which may be owing to the interannual variability of PW during these years.

\section{Measurements and data analysis}

Meteor observations have been performed at Collm since August 2004. The radar is a commercial SKiYMET system with one transmitting and 5 receiving antennas. The transmitting antenna is a 3-element Yagi antenna. The five receiving antennas being arranged in an asymmetric cross are forming an interferometer for meteor position detection. The radar operates at a frequency of $36.2 \mathrm{MHz}$ with a peak power of $6 \mathrm{~kW}$. Pulse repetition frequency was $2144 \mathrm{~Hz}$, effectively reduced to $536 \mathrm{~Hz}$ owing to 4-point coherent integration. The sampling resolution was $1.87 \mathrm{~ms}$. The angular and range resolutions are $\sim 2^{\circ}$ and $2 \mathrm{~km}$, respectively. The pulse width was $13 \mu \mathrm{s}$, and the receiver bandwidth was $50 \mathrm{kHz}$. In summer 2015, the radar had been replaced by a similar but slightly more effective system.

We use daily temperatures derived from the decay of individual underdense meteor trails (Hocking, 1999; Hocking et al., 2001). This provides a measure of the ambipolar diffusion coefficient, from whose vertical gradient the temperature at the height of the peak meteor flux can be obtained by employing a background temperature gradient climatology (Stober et al., 2008). The method delivers daily temperatures, and no decomposition into daily background temperatures and tides.

For comparison, we also use daily mean meridional winds measured by the radar. The radial winds at the line of sight of each meteor are obtained from the Doppler shift of the received individual radial winds minimizing the squared difference. The method assumes that vertical winds are small. The daily mean winds are determined by a least-squares fit of the mean, diurnal, and semidiurnal tidal components to the half-hourly means of one day. Further details can be found in Hocking et al. (2001) and Jacobi et al. (2007).

\section{Wavelet spectra of daily temperatures and winds}

An example of daily temperatures in the course of the year 2005 is shown in Fig. 1. The data represent the annual cycle of MLT temperatures, and considerable day-to-day vari-

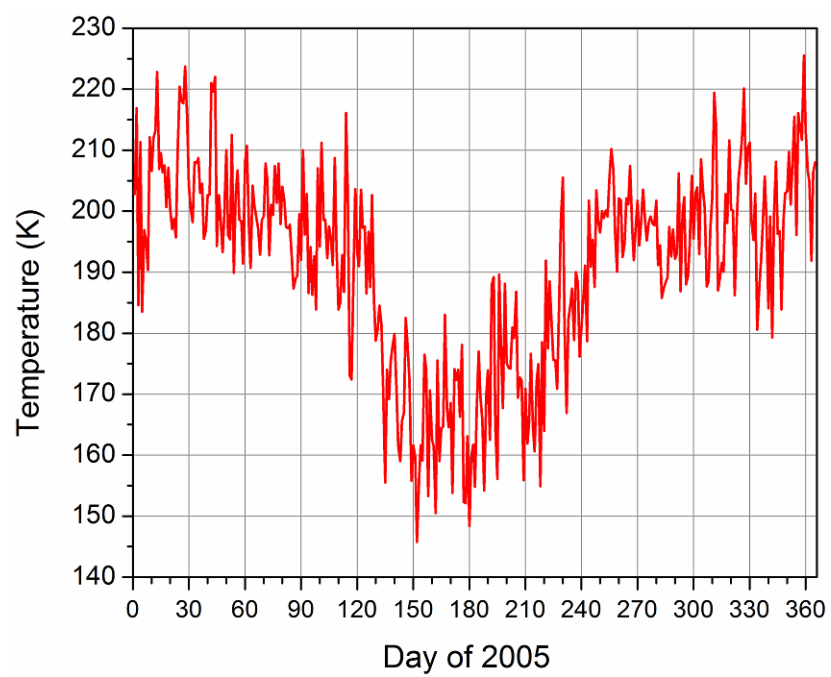

Figure 1. Temperatures observed by the Collm meteor radar in 2005.

ability especially during winter and summer. Morlet wavelet spectra (see, e.g., Torrence and Compo, 1998) obtained from the daily temperatures are shown in the left panel of Fig. 2. For longer periods in the period range of the quasi 10- and quasi 16-day wave there is a tendency for larger amplitudes (indicated by blue colour) during winter, while for shorter periods below 10 days, larger amplitudes are also found during summer. This is consistent with the known behaviour of the planetary waves in the MLT, so that the observed variations of temperatures may at least partly be the signature of planetary waves. For comparison, the wavelet spectra of the daily meridional winds are shown in the right panel of Fig. 2. Qualitatively, the seasonal distribution of wavelet amplitudes is the same as for the temperatures, although the very shortperiod oscillations ( $<3$ days, probably owing to the quasi 2day wave) are more expressed in the winds than in the temperatures.

Figure 3 presents a zoom into the wavelet spectra focusing on the winter of 2008/2009, which was characterized by a very strong major stratospheric warming (Manney et al., 2009; Labitzke and Kunze, 2009). The vertical lines represent the "central day" of the warming where the stratospheric winds and meridional temperature gradients reverse (see Matthias et al., 2012). The wavelet spectrum of the daily meridional winds in Fig. 3 (right) shows a change of main periods from longer periods around 15 days to shorter ones of about 10 days. This is similar to what has already been presented by Matthias et al. (2012) for meridional winds. The change in main period can also be seen in the temperatures in Fig. 3, indicating that temperature variations may be taken as a proxy for long-period MLT variations as well. 

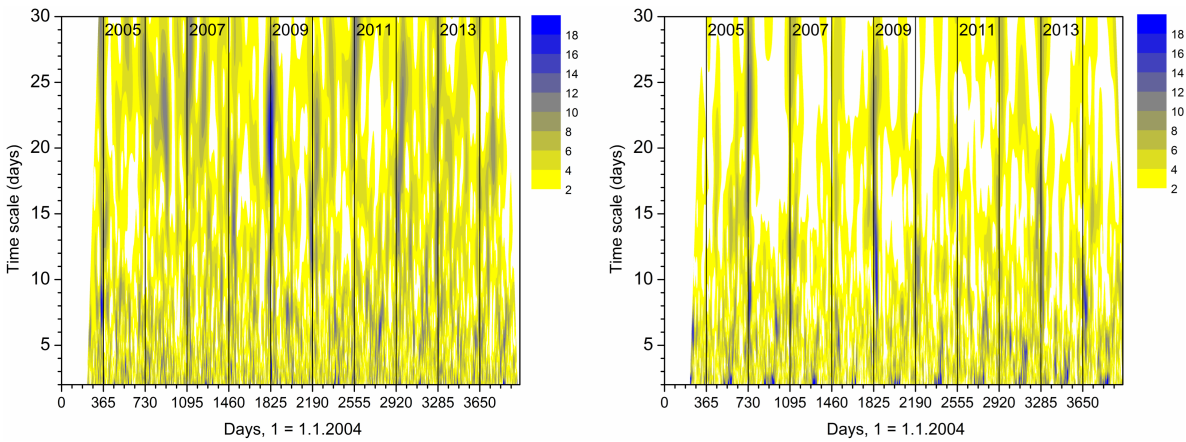

Figure 2. Wavelet spectra of daily temperatures (left) and meridional winds (right) over Collm.
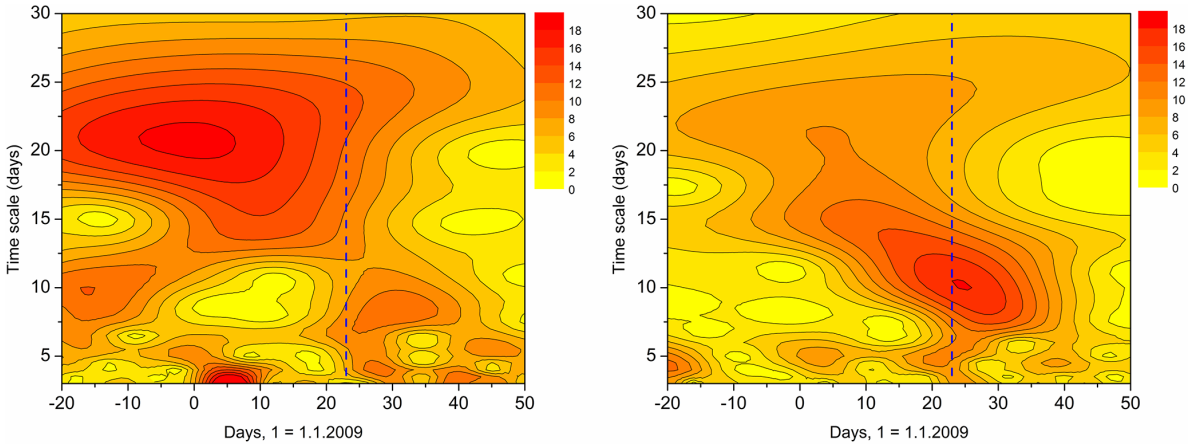

Figure 3. Wavelet spectra of daily temperatures (left) and meridional winds (right) over Collm during winter 2008/2009.

\section{Seasonal temperature oscillations}

In order to analyze the seasonal and interannual variability of temperature oscillations, following Jacobi et al. (1998a) we apply a filter technique by using Lanczos bandpass filters (Duchon, 1979) with 50 weights and cut-off periods of 4-6 and $8-12$ days, respectively. These cut-off-periods were used to obtain the signature of quasi 5- and quasi 10-day oscillations. From Figs. 2 and 3 one can also see that the long-period end of the wave energy burst during winter is not clearly defined and may change with time. Therefore, applying filter techniques to analyze the quasi 16-day wave as has been done by Jacobi et al. (1998a, 2008) for the winds is difficult and the results for the quasi 16-day oscillation depend on the highpass cut-off period chosen. As a result, the filtered time series would include not only the signature of planetary waves, but also the one of other irregular variation, e.g., owing to the effect of stratospheric warmings as in Fig. 3. We also do not consider very short periods shorter than 4 days, because this would include fluctuations at time scales smaller than 2 days and in addition also irregular fluctuations.

As a proxy for PW activity, the standard deviation of the daily filtered temperatures in a running 91 day window was calculated. This results in a time series of daily standard deviations. Figure 4 shows the 2005-2013 mean daily standard deviations. The greyshaded area shows the standard error derived from the 9 years of data. Note that there is a "jump" between the December and January values, which appears because the January and December values belong to different years. For the quasi 5-day wave, the jump is thus due to a combination of a positive decadal trend and particularly small/large values in January-February 2005/December 2013. The quasi-10-day wave was very strong in January 2004 and weak in December 2013, owing to a pronounced year-to-year variability in winter.

One can see from Fig. 4 that on an average the shorter periods (4-6 days period, upper panel of Fig. 4) have their maxima during both solstices, but with larger amplitudes in summer. Pancheva et al. (2010) have reported amplification of the westward quasi 5-day wave during equinoxes at 40 $50^{\circ} \mathrm{N}$, although for some years they also found amplification in summer. Liu et al. (2015) found that the 5-day waves of different wavenumbers maximise during late winter, but also show a maximum during summer especially for the westward travelling wavenumber 1 . These results, however, were made at polar latitudes. Jacobi et al. (1998a) analysing MLT wind data have found larger values in summer than in winter, and an indication for equinox maxima, but no maximum in winter. Ern et al. (2009) also reported equinox Rossby wave enhancements. It remains unclear, why there is no pronounced equinox maximum in the Collm temperature 5-day oscillations in Fig. 4. One possible reason may be that here all wavenumbers are included, while the satellite observa- 

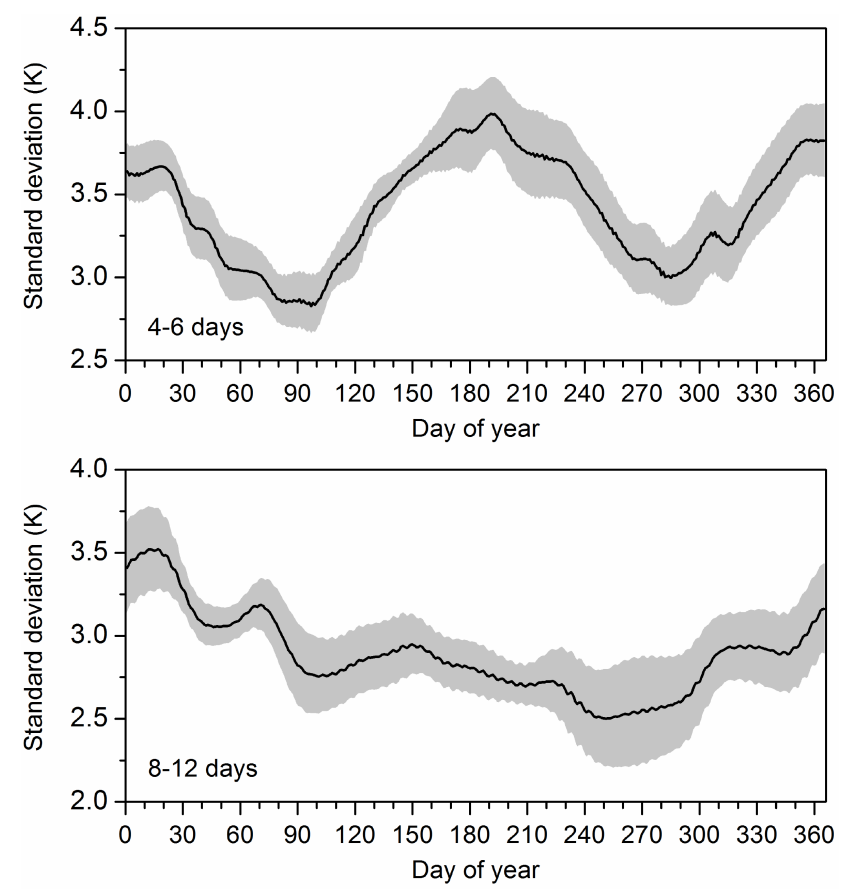

Figure 4. 2005-2013 mean daily standard deviations of temperatures filtered in the 4-6 days (upper panel) and 8-12 days (lower panel) period range. The greyshaded area shows the standard error derived from the 9 years of data.

tions are usually analysed with respect to waves of single wavenumbers.

The longer period oscillations (8-12 days period, lower panel of Fig. 4) maximize in winter (after winter solstice), and there is a secondary maximum in late winter/early spring. Also a weak autumn maximum is visible. Forbes and Zhang (2015) showed enhancement of the quasi 10-day wave in autumn and spring. This is partly seen in the wavelets, e.g., in 2012, but the average signature of the equinox enhancement is weak in the climatology in Figure 4. McDonald et al. (2011) reported also equinox enhancement for the 16-day wave. Again, these differences may be due to the fact that the radar observations cannot distinguish between waves of different wavenumbers.

The seasonal mean standard deviations for winter (December-February, DJF) and summer (June-August, JJA) have been calculated by taking the 91-day average standard deviations that were attributed to each 15 January and 15 July, respectively, in the time period from 2005 to 2013. The resulting time series are shown in Fig. 5. Note that there is sometimes a multi-peak structure visible in satellite data (e.g. McDonald et al., 2011, Forbes and Zhang, 2015), which can also be seen in the wavelet analyses in Fig. 3. These details are not reflected in these seasonal data, which therefore represent a mixed signal of mean amplitude and persistence of the oscillations. For the quasi 5-day wave (upper panel of Fig. 5) there is an increase of amplitudes during the time
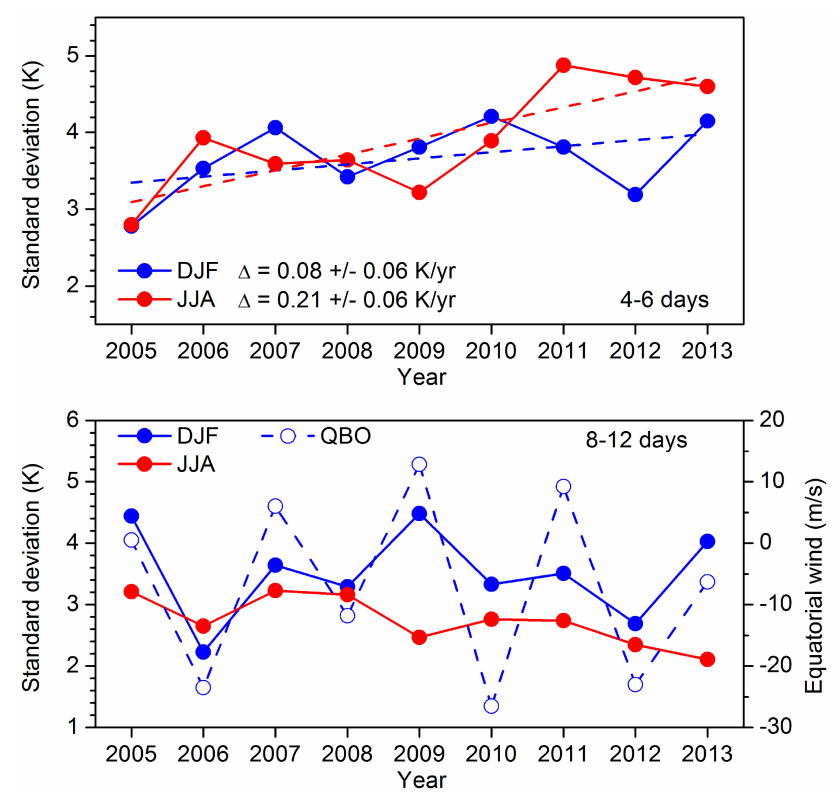

Figure 5. Time series of December-February (DJF, blue) and JuneAugust (JJA, red) mean daily standard deviations of temperatures filtered in the 4-6 days (upper panel) and 8-12 days (lower panel) period range. Linear fits are added to the $4-5$ day values. In the lower panel, the 3-monthly mean equatorial zonal winds at $30 \mathrm{hPa}$ are added (dashed blue line with open symbols).

interval under investigation. The increase of the 4-6 day oscillation in summer is significant at the $95 \%$ level according to a $t$ test, however, this is not the case in winter. Note that Pogoreltsev et al. (2009) reported a decrease of the quasi 5day wave at $30 \mathrm{hPa}$ between 1959 and 2007 . Therefore, we cannot distinguish whether the increase of the 5-day signature during recent years is the result of interdecadal variations or a possible change of trends. At the interannual time scale, no clear tendency of quasi 5-day variability is visible. In particular, an influence of the equatorial QBO, as has been found by Miyoshi and Hirooka (2003) using NCEP reanalyses or Pancheva et al. (2010) using SABER/TIMED data, is not seen in the radar temperatures.

Considering the quasi 10-day signature of Collm MLT temperatures in winter (lower panel of Fig. 5), a clear trend is not seen, but a pronounced biennial signature is visible in winter, which well coincides with the equatorial stratospheric $\mathrm{QBO}$ at $30 \mathrm{hPa}$. Lu et al. (2012) reported that planetary waves with periods of 11-13 days appear to be modulated by the QBO but the effect was non-stationary. The increased PW activity during QBO westerly phase conditions has also been modeled. For example, Naito and Yoden (2006) used a simple mechanistic model, and found that the upward EP-flux in the midlatitude stratosphere is significantly larger during the QBO westerly phase than during the QBO easterly phase. This biennial oscillation is not seen in summer MLT temperatures over Collm. Espy et al. (1997) and Jacobi et al. (1998b) 
have presented some evidence for a possible QBO influence on the quasi 16-day wave activity in summer, which, however, cannot be confirmed by our temperature measurements.

\section{Conclusions}

On the basis of the temperature measurements we analyzed day-to-day fluctuations which are possibly caused by PW. For all periods, the amplitudes are stronger during solstices than during equinoxes. In summer (winter) oscillations with periods smaller (larger) than 6 days dominate the day-to-day variability. This behaviour is visible both in temperature and meridional wind fluctuations. We analyzed the seasonal and interannual variability of the quasi 5 - and quasi 10-day waves from 2005 to 2013 applying filter techniques. While the quasi 5-day wave showed a quasi-continuous increase during the time interval under investigation, no trend was visible for the quasi 10-day wave. This wave, however, showed a clear correlation with the equatorial QBO, such that the amplitudes were stronger during the QBO westerly phase than during the QBO easterly phase. This behaviour, however, was only found for the winter season.

Acknowledgements. Equatorial winds have been provided by the Institute of Meteorology of the Freie Universität Berlin through http://www.geo.fu-berlin.de/en/met/ag/strat/produkte/qbo/.

We acknowledge support from the German Research Foundation (DFG) and Universität Leipzig within the program of Open Access Publishing.

Edited by: M. Förster

Reviewed by: two anonymous referees

\section{References}

Bittner, M., Offermann, D., and Graef, H.-H.: Mesopause temperature variability above a midlatitude station in Europe, J. Geophys. Res., 105, 2045-2058, doi:10.1029/1999JD900307, 2000.

Bittner, M., Offermann, D., Graef, H.-H., Donner, M., and Hamilton, K.: An 18-year time series of $\mathrm{OH}$ rotational temperatures and middle atmosphere decadal variations, J. Atmos. Sol.-Terr. Phys., 64, 1147-1166, doi:10.1016/S1364-6826(02)00065-2, 2002.

Duchon, C. E.: Lanczos Filtering in one and two dimensions, J. Appl. Meteorol., 18, 1016-1022, doi:10.1175/15200450(1979)018<1016:LFIOAT>2.0.CO;2, 1979.

Ern, M., Lehmann, C., Kaufmann, M., and Riese, M.: Spectral wave analysis at the mesopause from SCIAMACHY airglow data compared to SABER temperature spectra, Ann. Geophys., 27, 407416, doi:10.5194/angeo-27-407-2009, 2009.

Espy, P. J., Stegman, J., and Witt, G.: Interannual variations of the quasi-16-day oscillation in the polar summer mesospheric temperature, J. Geophys. Res., 102, 1983-1990, doi:10.1029/96JD02717, 1997.

Forbes, J. M.: Tidal and planetary waves, in: The Upper Mesosphere and Lower Thermosphere: A Review of Experiment and Theory, edited by: Johnson, R. M. and Killeen, T. L., Geophysical Monographs, 67, ISBN 0-87590-044-5, 67-87, 1995.

Forbes, J. M. and Zhang, X.: Quasi-10-day wave in the atmosphere, J. Geophys. Res. Atmos., 120, 11079-11089, doi:10.1002/2015JD023327, 2015.

Hocking, W. K.: Temperatures using radar-meteor decay times, Geophys. Res. Lett., 26, 3297-3300, doi:10.1029/1999GL003618, 1999.

Hocking, W. K., Fuller, B., and Vandepeer, B.: Real-time determination of meteor-related parameters utilizing modern digital technology, J. Atmos. Solar-Terr. Phys., 63, 155-169, doi:10.1016/S1364-6826(00)00138-3, 2001.

Jacobi, Ch., Schminder, R., and Kürschner, D.: Planetary wave activity obtained from long-term (2-18 days) variations of mesopause region winds over Central Europe $\left(52^{\circ} \mathrm{N}, 15^{\circ} \mathrm{E}\right)$, J. Atmos. Sol.-Terr. Phys., 60, 81-93, doi:10.1016/S13646826(97)00117-X, 1998a.

Jacobi, Ch., Schminder, R., and Kürschner, D.: Long-period (12-25 days) oscillations in the summer mesopause region as measured at Collm $\left(52^{\circ} \mathrm{N}, 15^{\circ} \mathrm{E}\right)$ and their dependence on the equatorial quasi-biennial oscillation, Contrib. Atmos. Phys., 71, 461-464, 1998b.

Jacobi, Ch., Fröhlich, K., Viehweg, C., Stober, G., and Kürschner, D.: Midlatitude mesosphere/lower thermosphere meridional winds and temperatures measured with Meteor Radar, Adv Space Res., 39, 1278-1283, doi:10.1016/j.asr.2007.01.003, 2007.

Jacobi, Ch., Hoffmann, P., and Kürschner, D.: Trends in MLT region winds and planetary waves, Collm $\left(52^{\circ} \mathrm{N}, 15^{\circ} \mathrm{E}\right)$, Ann. Geophys., 26, 1221-1232, doi:10.5194/angeo-26-1221-2008, 2008.

Labitzke, K. and Kunze, M.: Über die unerwartet warme Stratosphäre im Winter 2008/2009, Beiträge zur Berliner Wetterkarte, 27/09, SO 13/9, 8 pp., 2009.

Liu, X., Yue, J., Xu, J., Yuan, W., Russell III, J. M., and Hervig, M. E.: Five-day waves in polar stratosphere and mesosphere temperature and mesospheric ice water measured by SOFIE/AIM, J. Geophys. Res. Atmos., 120, 3872-3887, doi:10.1002/2015JD023119, 2015.

Lu, H., Pancheva, D., Mukhtarov, P., and Cnossen, I.: QBO modulation of traveling planetary waves during northern winter, J. Geophys. Res., 117, D09104, doi:10.1029/2011JD016901, 2012.

Manney, G. L., Schwartz, M. J., Krueger, K., Santee, M. L., Pawson, S., Lee, J. N., Daffer, W. H., Fuller, R. A., and Livesey, N. J.: Aura Microwave Limb Sounder observations of dynamics and transport during the record-breaking 2009 arctic stratospheric major warming, Geophys. Res. Lett., 36, L12815, doi:10.1029/2009GL038586, 2009.

Matthias, V., Hoffmann, P., Rapp, M., and Baumgarten, G.: Composite analysis of the temporal development of waves in the polar MLT region during stratospheric warmings, J. Atmos. Sol.-Terr. Phys., 90-91, 86-96, doi:10.1016/j.jastp.2012.04.004, 2012.

McDonald, A. J., Hibbins, R. E., and Jarvis, M. J.: Properties of the quasi 16 day wave derived from EOS MLS observations, J. Geophys. Res., 116, D06112, doi:10.1029/2010JD014719, 2011.

Miyoshi, Y. and Hirooka, T.: Quasi-biennial variation of the 5day wave in the stratosphere, J. Geophys. Res., 108, 4620, doi:10.1029/2002JD003145, 2003.

Naito, Y. and Yoden, S.: Behavior of planetary waves before and after stratospheric sudden warming events in several 
phases of the equatorial QBO, J. Atmos. Sci., 63, 1637-1649, doi:10.1175/JAS3702.1, 2006.

Pancheva, D., Mukhtarov, P., Andonov, B., and Forbes, J. M.: Global distribution and climatological features of the 5-6day planetary waves seen in the SABER/TIMED temperatures (2002-2007), J. Atmos. Sol.-Terr. Phys., 72, 26-37, doi:10.1016/j.jastp.2009.10.005, 2010.

Pogoreltsev, A. I., Kanukhina, A. Yu., Suvorova, E. V., and Savenkova, E. N.: Variability of planetary waves as a signature of possible climatic changes, J. Atmos. Sol.-Terr. Phys., 71, 15291539, doi:10.1016/j.jastp.2009.05.011, 2009.
Stober. G., Jacobi, Ch., Fröhlich, K., and Oberheide, J.: Meteor radar temperatures over Collm $\left(51.3^{\circ} \mathrm{N}, 13^{\circ} \mathrm{E}\right)$, Adv. Space Res., 42, 1253-1258, doi:10.1016/j.asr.2007.10.018, 2008.

Stober, G., Jacobi, Ch., Matthias, V., Hoffmann, P., and Gerding, M.: Neutral air density variations during strong planetary wave activity in the mesopause region derived from meteor radar observations, J. Atmos. Sol.-Terr. Phys., 74, 55-63, doi:10.1016/j.jastp.2011.10.007, 2012.

Torrence, C. and Compo, G.P.: A practical guide to wavelet analysis, B. Am. Meteorol. Soc., 79, 61-78, doi:10.1175/BAMS-D13-00192.1, 1998. 